\title{
Diagnostic Factor
}

National Cancer Institute

\section{Source}

National Cancer Institute. Diagnostic Factor. NCI Thesaurus. Code C19591.

A biological, physiological, behavioral, or molecular indicator of the presence or predisposition towards development of a specific disease. 